\title{
Thioether-linked azobenzene-based liquid crystal dimers exhibiting the twist-bend nematic phase over a wide temperature range
}

\author{
Yuki Arakawa*, Kenta Komatsu, Yuko Ishida and Hideto Tsuji \\ Department of Applied Chemistry and Life Science, Graduate School of Engineering, \\ Toyohashi University of Technology, 1-1 Hibarigaoka, Tempaku-cho, Toyohashi, Aichi, \\ 441-8580 Japan
}

E-mail: arakawa@tut.jp

Two homologous series of sulfur-containing thioether-linked 4cyanoazobenzene-based liquid crystal (LC) dimers were developed: a symmetric series based on 4-cyanoazobenzene arms $[(\mathrm{CN}) \mathrm{AzoS} n \mathrm{SAzo}(\mathrm{CN})]$ and a non-symmetric series based on 4cyanoazobenzene and 4-cyanobiphenyl arms [(CN)AzoSnSCB]. They contained different flexible oligomethylene spacers $\left(\mathrm{C}_{n} \mathrm{H}_{2 n}\right)$ consisting of odd numbers of carbon atoms $(n=3,5,7,9$, and 11). The symmetric (CN)AzoSnSAzo $(\mathrm{CN})$ dimers with $n=5,7,9$, and 11 showed an elusive monotropic twist-bend nematic $\left(\mathrm{N}_{\mathrm{TB}}\right)$ phase, while all the non-symmetric (CN)AzoSnSCB dimers exhibited the $\mathrm{N}_{\text {TB }}$ phase. Notably, the $\mathrm{N}_{\text {TB }}$ phase observed for non-symmetric $(\mathrm{CN}) \mathrm{AzoS} 7 \mathrm{SCB}$ could be supercooled to room temperature, leading to a glassy $\mathrm{N}_{\mathrm{TB}}$ phase. (CN)AzoS9SCB showed a similar tendency accompanied by partial crystallization. These are the first reported examples of azobenzene-based LC dimers exhibiting a broad temperature range of $\mathrm{N}_{T B}$ phases supercooled to room temperature. Such prominent stability of the $\mathrm{N}_{\mathrm{TB}}$ phase is due to the supercooling effect assisted by the synergy of molecular bend arising from thioether linkages and non-symmetric mesogenic arms. The phase-transition temperatures were overall higher for symmetric $(\mathrm{CN}) \mathrm{AzoSnSAzo}(\mathrm{CN})$ than for nonsymmetric $(\mathrm{CN}) \mathrm{AzoS} n \mathrm{SCB}$. It is assumed that the difference in the mesogenic arm structures hardly influenced their molecular geometry or anisotropy in terms of entropy changes. 


\section{Introduction}

In addition to the conventional nematic $(\mathrm{N})$ phase, unknown $\mathrm{N}\left(\mathrm{N}_{\mathrm{x}}\right)$ phases without apparent layer structures are occasionally observed for polymers [1], bent dimers connected with odd numbers of spacers [2-4], bent-core molecules [5,6], and a tetrapodtype molecule [7]. The twist-bend nematic $\left(\mathrm{N}_{\mathrm{TB}}\right)$ phase is an example of such an $\mathrm{N}_{\mathrm{x}}$ phase with a heliconical helix, in which the local director tilts from the helical axis. This renders the $\mathrm{N}_{\text {TB }}$ phase distinct from the conventional chiral $\mathrm{N}$ phase (or cholesteric phase), in which the local director is perpendicular to the helical axis. The theoretical possibility of the $\mathrm{N}_{\mathrm{TB}}$ phase was originally predicted by Meyer [8] and later extended by Dozov [9] and simulated by Memmer [10]. In-depth reinvestigation of an LC dimer comprising two 4cyanobiphenyl arms connected by a heptamethylene spacer, 1",7"-bis(4-cyanobiphenyl4'-yl)heptane (CB7CB) indicated that the $\mathrm{N}_{\mathrm{x}}$ phase is the $\mathrm{N}_{\text {TB }}$ phase [11] (here, it is to be noted that the $\mathrm{N}_{\mathrm{x}}$ phase observed for the tetrapod molecule reported recently by Mandle et al. was distinguished from the $\mathrm{N}_{\text {TB }}$ phase [7]). Thus, identification of the $\mathrm{N}_{\mathrm{TB}}$ phase inspired extensive study on a large number of molecules that exhibit the $\mathrm{N}_{\mathrm{TB}}$ phase, such as bent LC dimers [12-36], various oligomers [35,37-46], polymers [47], and bent-core molecules [48,49], and on related potential applications [50-54]. Electro-optical analysis [55], transmission electron microscopy [56,57], and soft, tender, and hard resonant X-ray scattering [34,58-61] confirmed that the helical pitch of the $\mathrm{N}_{T B}$ phase is considerably short, typically the length of several molecules or 10-20 nm. On the other hand, another heliconical model for the $\mathrm{N}_{\mathrm{x}}$ phase, identified as the $\mathrm{N}_{\mathrm{TB}}$ phase, was proposed, and it was named the polar twisted nematic $\left(\mathrm{N}_{\mathrm{PT}}\right)$ phase [62-66]. It has been suggested that the identification of the $\mathrm{N}_{T B}$ phase to date is inadequate: the $\mathrm{N}_{\mathrm{x}}$ phase identified as the $\mathrm{N}_{T B}$ phase is different from the true $\mathrm{N}_{\mathrm{TB}}$ phase predicted originally by Meyer. The heliconical 
models and terms involving the $\mathrm{N}_{\mathrm{TB}}$ or $\mathrm{N}_{\mathrm{PT}}$ phase are still under debate. As of now, the widely prevalent term ' $\mathrm{N}_{\text {Tв }}$ phase' is used tentatively in this paper.

With respect to both scientific viewpoints and practical applications, azobenzene is an important building block for LC materials owing to its ability to undergo trans-cis photoisomerisation [67], leading to light-induced phase transitions [68-72] and development of photo-mobile materials [73-75], light-induced alignment technologies [76-80], light-induced chiral segregation [81,82], and molecular designs for supramolecular functional materials [82-86]. To date, several azobenzene-containing twist-bend nematogenic dimers have been developed [24-26], and the light-induced phase transition has been verified $[24,87]$. However, azobenzene-based LC dimers that exhibit the $\mathrm{N}_{\mathrm{T}}$ phase over a broad temperature range, including room temperature, have yet to be established.

In this study, we devised two homologous series of thioether-linked azobenzenebased LC dimers: symmetric dimers based on 4-cyanoazobenzene arms $[(\mathrm{CN}) \mathrm{AzoS} n \mathrm{SAzo}(\mathrm{CN})]$, and non-symmetric dimers based on 4-cyanoazobenzene and 4cyanobiphenyl arms $[(\mathrm{CN}) \mathrm{AzoSnSCB}]$. Different flexible oligomethylene spacers $\left(\mathrm{C}_{n} \mathrm{H}_{2 n}\right)$ with carbon numbers of $n=3,5,7,9$, and 11 were used. $\mathrm{CN}$, Azo, S, and CB refer to the cyano groups, azobenzene arms, thioether linkages, and 4-cyanobiphenyl arms, respectively (Figure 1). Previously, we reported that a symmetric (CN)AzoS7SAzo(CN) with a heptamethylene spacer exhibits the monotropic $\mathrm{N}_{\mathrm{TB}}$ phase [35]. However, the development of homologues is needed to ascertain the effect of the spacer length on the $\mathrm{N}_{\mathrm{TB}}$ phase. In addition, the combination of non-symmetric mesogenic arms and thioether linkages has a highly beneficial effect in inducing and broadening the $\mathrm{N}_{\text {TB }}$ phase [36]. Aligned with this strategy, the asymmetric series of (CN)AzoSnSCB with a 4- 
cyanobiphenyl arm was designed. We investigated the phase-transition behaviour of the dimers and conducted phase identification using polarising light optical microscopy (POM), differential scanning calorimetry (DSC), and X-ray diffraction (XRD) measurements.
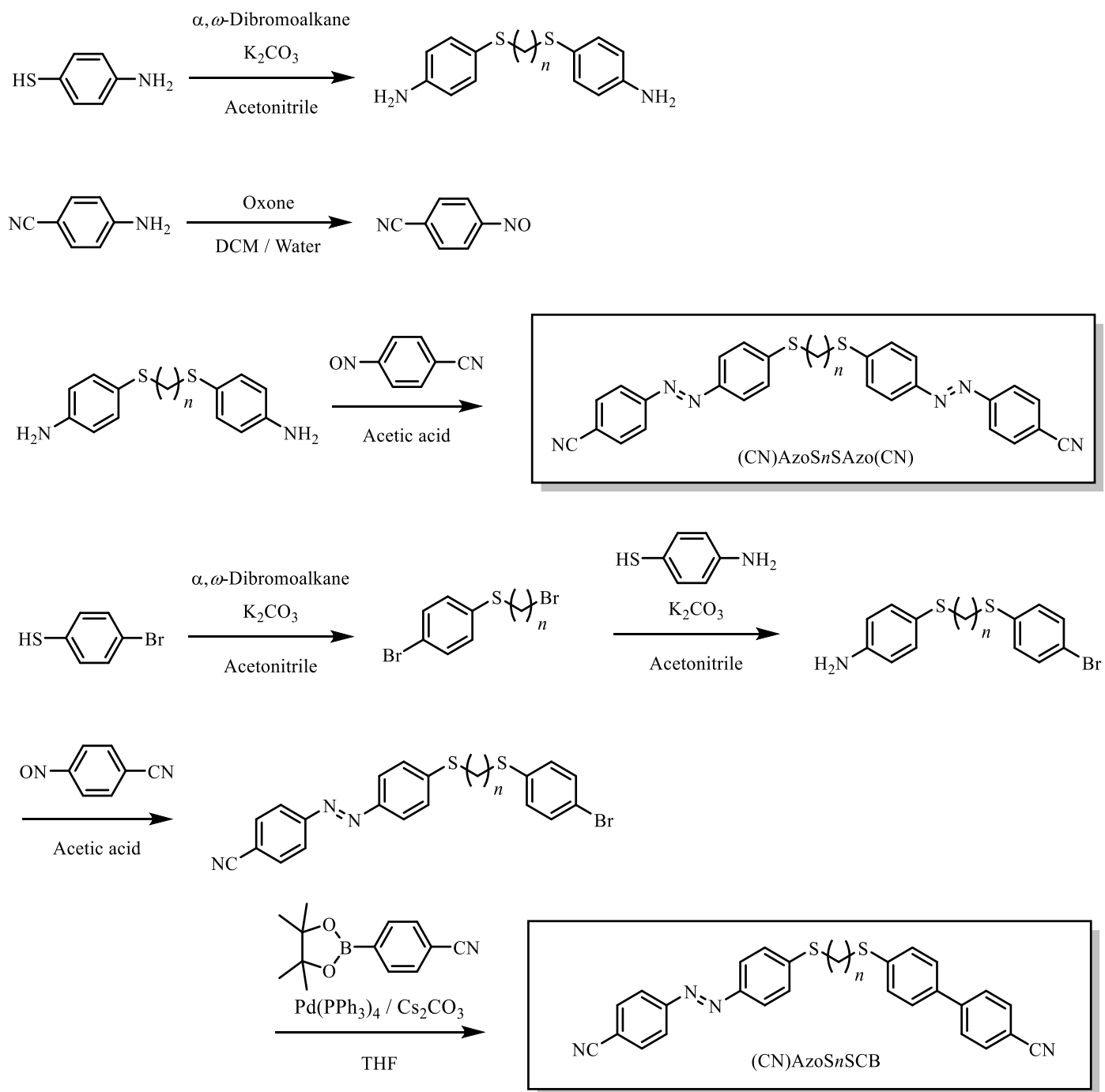

Figure 1. Synthetic pathways to prepare symmetric $(\mathrm{CN}) \mathrm{AzoS} n \mathrm{SAzo}(\mathrm{CN})$ and nonsymmetric (CN)AzoSnSCB. 


\section{Experimental Methods}

\section{Methods and instruments}

All chemicals were commercially available and used as received. The synthetic pathways are shown in Figure 1. The symmetric $(\mathrm{CN}) \mathrm{AzoS} n \mathrm{SAzo}(\mathrm{CN})$ dimers were synthesised according to the previously reported procedures for $(\mathrm{CN}) \mathrm{AzoS7SAzo}(\mathrm{CN})$ [35], and the asymmetric $(\mathrm{CN}) \mathrm{AzoSnSCB}$ dimers were synthesised according to the procedures for $(\mathrm{CN})$ AzoS7SCB, which are described in the following section. The molecular structures were characterised using ${ }^{1} \mathrm{H}$ and ${ }^{13} \mathrm{C}$ nuclear magnetic resonance (NMR) spectroscopy (see the Supporting Information), recorded on a JNM-ECX500 (500 MHz for ${ }^{1} \mathrm{H}$ NMR and $126 \mathrm{MHz}$ for ${ }^{13} \mathrm{C} \mathrm{NMR}$ ) instrument (JEOL Ltd., Tokyo, Japan), and highperformance liquid chromatography/high resolution mass spectrometry (HPLC/HRMS) with Agilent 1200 HPLC-Chip and 6520 Accurate-Mass Q-TOF. The characterisation details of intermediates and final compounds are described in the Supporting Information. The phase-transition behaviour was studied using POM with an Olympus polarised optical microscope (BX50, Tokyo, Japan) and a Linkam (Surrey, UK) temperature controller LK-600PM, and DSC with a Shimadzu DSC 60 (Kyoto, Japan) at a rate of $10{ }^{\circ} \mathrm{C} \mathrm{min}-1$ under a nitrogen gas flow of $50 \mathrm{~mL} \mathrm{~min}^{-1}$. The reproducibility of the DSC measurements was confirmed by repeating the measurements on a few specimens for each compound. The POM images and DSC results of all compounds are either shown in the main text or the Supporting Information. XRD measurements were conducted using a Bruker D8 DISCOVER diffractometer ( $\mathrm{Cu} \mathrm{K \alpha}$ radiation) equipped with a Vantec-500 detector. The specimens, kept in capillary glass tubes of $1.5 \mathrm{~mm}$ diameter (purchased from WJM-Glass Müller $\mathrm{GmbH})$, were aligned under a magnetic field $(B=300 \mathrm{mT})$. 


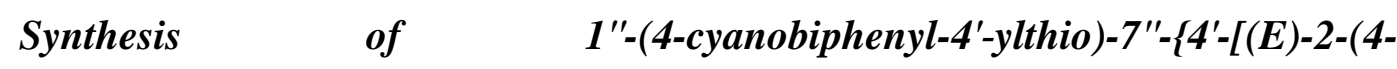
cyanophenyl)diazenyl]phenylthio\}heptane [(CN)AzoS7SCB]

\section{1'-Bromo-7'-(4-bromophenylthio)heptane}

This compound was synthesised referring to procedures in the literature [36]. 4Bromobenzenethiol (1.00 g, $5.29 \mathrm{mmol})$, 1,7-dibromoheptane (2.04 g, $7.91 \mathrm{mmol})$, $\mathrm{K}_{2} \mathrm{CO}_{3}(2.18 \mathrm{~g}, 15.8 \mathrm{mmol})$, and acetonitrile $(60 \mathrm{~mL})$ were added into a flask and the mixture was stirred at ambient temperature for $12 \mathrm{~h}$. The reacted mixture was extracted with dichloromethane (DCM) and washed with water and brine. The organic phase was dried over $\mathrm{MgSO}_{4}$ and the volatiles were removed under reduced pressure. The residue was purified by column chromatography on silica gel with an eluent of DCM/hexane = 1/25 (v/v). The NMR spectral data were similar to those described in Ref. 36.

\section{1'-(4-Aminophenylthio)-7'-(4-bromophenylthio)heptane}

1'-Bromo-7'-(4-bromophenylthio)heptane (0.700 g, $1.91 \mathrm{mmol})$, 4-aminobenzenethiol (0.251 g, $2.01 \mathrm{mmol}), \mathrm{K}_{2} \mathrm{CO}_{3}(0.833 \mathrm{~g}, 6.03 \mathrm{mmol})$, and acetone $(15 \mathrm{~mL})$ were added into a $50 \mathrm{~mL}$ flask and the mixture was stirred at ambient temperature for $5 \mathrm{~h}$. The reaction mixture was extracted with DCM and washed with water and brine. The organic phase was dried over $\mathrm{MgSO}_{4}$ and the volatiles were removed under reduced pressure. The residue was purified by column chromatography on silica gel with an eluent of DCM/hexane $=3 / 1(\mathrm{v} / \mathrm{v})$. Yield: $92 \% .{ }^{1} \mathrm{H}$ NMR $\left(500 \mathrm{MHz}, \mathrm{CDCl}_{3}\right) \delta 7.38(\mathrm{~d}, J=8.5 \mathrm{~Hz}$, $\operatorname{Ar}-H, 2 \mathrm{H}), 7.22(\mathrm{~d}, J=8.5 \mathrm{~Hz}, \operatorname{Ar}-H, 2 \mathrm{H}), 7.16(\mathrm{~d}, J=8.5 \mathrm{~Hz}, \operatorname{Ar}-H, 2 \mathrm{H}), 6.61(\mathrm{~d}, J=$ $8.5 \mathrm{~Hz}, \mathrm{Ar}-H, 2 \mathrm{H}), 3.68\left(\mathrm{~s}, \mathrm{Ar}-\mathrm{NH}_{2}, 2 \mathrm{H}\right), 2.87\left(\mathrm{t}, J=7.5 \mathrm{~Hz}, \mathrm{~S}-\mathrm{CH}_{2}, 2 \mathrm{H}\right), 2.75(\mathrm{t}, J=$ $\left.7.5 \mathrm{~Hz}, \mathrm{~S}-\mathrm{CH}_{2}, 2 \mathrm{H}\right), 1.61$ (tt, $J=7.5$ and $\left.7.8 \mathrm{~Hz}, \mathrm{~S}-\mathrm{CH}_{2}-\mathrm{CH}_{2}, 2 \mathrm{H}\right), 1.55$ (tt, $J=7.3$ and $\left.7.5 \mathrm{~Hz}, \mathrm{~S}-\mathrm{CH}_{2}-\mathrm{CH}_{2}, 2 \mathrm{H}\right), 1.43-1.33\left(\mathrm{~m}, \mathrm{~S}-\left(\mathrm{CH}_{2}\right)_{2}-\mathrm{CH}_{2}, 4 \mathrm{H}\right), 1.32-1.23\left(\mathrm{~m}, \mathrm{~S}-\left(\mathrm{CH}_{2}\right)_{3}-\right.$ 
$\left.\mathrm{CH}_{2}, 2 \mathrm{H}\right) \mathrm{ppm} .{ }^{13} \mathrm{C} \mathrm{NMR}\left(126 \mathrm{MHz}, \mathrm{CDCl}_{3}\right) \delta 145.7,136.2,133.7,133.7,131.8,131.8$, $130.3,130.3,123.7,119.3,115.5,115.5,36.3,33.5,29.2,28.8,28.62,28.56,28.4$ ppm.

1"-(4-Bromophenylthio)-7"- $\left\{4^{\prime}-[(E)-2-(4-\right.$ cyanophenyl)diazenyl]phenylthio\}heptane

This compound was synthesised referring to procedures in the literature [35]. A solution of Oxone ${ }^{\circledR}(0.375 \mathrm{~g}, 22.0 \mathrm{mmol})$ in distilled water $(8 \mathrm{~mL})$ was added to a solution of 4aminobenzonitrile $(0.144 \mathrm{~g}, 1.22 \mathrm{mmol})$ dissolved in DCM $(2 \mathrm{~mL})$ in a $50 \mathrm{~mL}$ two-necked flask, which was stirred at room temperature under an argon atmosphere. After $9 \mathrm{~h}$, the reaction mixture was extracted with DCM, and the organic phase was washed with $1 \mathrm{M}$ $\mathrm{HCl}$ aq. and brine, and then the volatiles were removed under reduced pressure. The product (4-nitrosobenzonitrile) was used for the next step without further purification. 1'(4-Aminophenylthio)-7'-(4-bromophenylthio)heptane $(0.250 \mathrm{~g}, 0.609 \mathrm{mmol})$ and acetic acid $(10 \mathrm{~mL})$ were added into a $50 \mathrm{~mL}$ two-necked flask with all amount of the obtained 4-nitrosobenzonitrile, and the mixture was stirred at room temperature for $12 \mathrm{~h}$ under an argon atmosphere. The reaction mixture was then extracted with DCM, the organic phase was washed with water and brine and dried over $\mathrm{MgSO}_{4}$, and the volatiles were evaporated under reduced pressure. The residue was purified by column chromatography on silica gel with an eluent of DCM/hexane $=2 / 1(\mathrm{v} / \mathrm{v})$ and recrystallised in a mixed solvent of methanol/DCM. Yield: 87\%. ${ }^{1} \mathrm{H}$ NMR (500 MHz, $\left.\mathrm{CDCl}_{3}\right) \delta 7.96(\mathrm{~d}, J=8.5$ $\mathrm{Hz}, \mathrm{Ar}-H, 2 \mathrm{H}), 7.87(\mathrm{~d}, J=8.5 \mathrm{~Hz}, \mathrm{Ar}-H, 2 \mathrm{H}), 7.80(\mathrm{~d}, J=9.0 \mathrm{~Hz}, \mathrm{Ar}-H, 2 \mathrm{H}), 7.38(\mathrm{~d}$, $J=8.5 \mathrm{~Hz}, \mathrm{Ar}-H, 2 \mathrm{H}), 7.38(\mathrm{~d}, J=8.5 \mathrm{~Hz}, \mathrm{Ar}-H, 2 \mathrm{H}), 7.17(\mathrm{~d}, J=9.0 \mathrm{~Hz}, \operatorname{Ar}-H, 2 \mathrm{H})$, $3.01\left(\mathrm{t}, J=7.5 \mathrm{~Hz}, \mathrm{~S}-\mathrm{CH}_{2}, 2 \mathrm{H}\right), 2.89\left(\mathrm{t}, J=7.5 \mathrm{~Hz}, \mathrm{~S}-\mathrm{CH}_{2}, 2 \mathrm{H}\right), 1.72(\mathrm{tt}, J=7.5$ and 7.5 $\left.\mathrm{Hz}, \mathrm{S}-\mathrm{CH}_{2}-\mathrm{CH}_{2}, 2 \mathrm{H}\right), 1.64\left(\mathrm{tt}, J=7.3\right.$ and $\left.7.5 \mathrm{~Hz}, \mathrm{~S}-\mathrm{CH}_{2}-\mathrm{CH}_{2}, 2 \mathrm{H}\right), 1.52-1.39(\mathrm{~m}, \mathrm{~S}-$ 
$\left.\left(\mathrm{CH}_{2}\right)_{2}-\mathrm{CH}_{2}, 4 \mathrm{H}\right), 1.39-1.31\left(\mathrm{~m}, \mathrm{~S}-\left(\mathrm{CH}_{2}\right)_{3}-\mathrm{CH}_{2}, 2 \mathrm{H}\right) \mathrm{ppm} .{ }^{13} \mathrm{C} \mathrm{NMR}\left(126 \mathrm{MHz}, \mathrm{CDCl}_{3}\right)$ $\delta 154.6,149.8,143.9,136.1,133.2,133.2,131.8,131.8,130.3,130.3,127.1,127.1,123.8$, $123.8,123.2,123.2,119.4,118.5,113.6,33.6,32.2,28.8,28.7,28.6,28.6,28.5 \mathrm{ppm}$.

1"-(4-Cyanobiphenyl-4'-ylthio)-7"'-\{4'-[(E)-2-(4cyanophenyl)diazenyl]phenylthio theptane [(CN)AzoS7SCB] 1"-(4-Bromophenylthio)-7"'-\{4'-[(E)-2-(4-cyanophenyl)diazenyl]phenylthio $\}$ heptane (0.257 g, $0.490 \mathrm{mmol})$, 4-cyanophenylboronic acid pinacol ester $(0.135 \mathrm{~g}, 0.588 \mathrm{mmol})$, $\mathrm{Cs}_{2} \mathrm{CO}_{3}(0.384 \mathrm{~g}, 1.18 \mathrm{mmol})$, and $\mathrm{Pd}\left(\mathrm{PPh}_{3}\right)_{4}(67.9 \mathrm{mg}, 58.8 \mu \mathrm{mol})$ were put in a $50 \mathrm{~mL}$ two-necked flask, and then degassed tetrahydrofuran (THF) $(7 \mathrm{~mL})$ (degassed by bubbling argon gas) was added into the flask. The solution was stirred at reflux temperature under an argon atmosphere. After $18 \mathrm{~h}$, the reaction mixture was cooled to ambient temperature, extracted with DCM, and washed with water and brine. The organic phase was dried over $\mathrm{MgSO}_{4}$ and the volatiles were evaporated under reduced pressure. The residue was purified by column chromatography on silica gel with an eluent of $\mathrm{DCM} /$ hexane $=2 / 1(\mathrm{v} / \mathrm{v})$ and recrystallisation in a mixed solvent of DCM/hexane. Yield: 77\%. ${ }^{1} \mathrm{H}$ NMR $\left(500 \mathrm{MHz}, \mathrm{CDCl}_{3}\right) \delta 7.95(\mathrm{~d}, J=8.5 \mathrm{~Hz}, \mathrm{Ar}-H, 2 \mathrm{H}), 7.87(\mathrm{~d}, J=9.0 \mathrm{~Hz}$, $\operatorname{Ar}-H, 2 \mathrm{H}), 7.80(\mathrm{~d}, J=8.5 \mathrm{~Hz}, \mathrm{Ar}-H, 2 \mathrm{H}), 7.70(\mathrm{~d}, J=9.0 \mathrm{~Hz}, \mathrm{Ar}-H, 2 \mathrm{H}), 7.65(\mathrm{~d}, J=$ $8.5 \mathrm{~Hz}, \mathrm{Ar}-H, 2 \mathrm{H}), 7.50(\mathrm{~d}, J=8.5 \mathrm{~Hz}, \mathrm{Ar}-H, 2 \mathrm{H}), 7.38(\mathrm{~d}, J=8.5 \mathrm{~Hz}, \mathrm{Ar}-H, 2 \mathrm{H}), 7.37$ $(\mathrm{d}, J=8.5 \mathrm{~Hz}, \mathrm{Ar}-H, 2 \mathrm{H}), 3.02\left(\mathrm{t}, J=7.3 \mathrm{~Hz}, \mathrm{~S}-\mathrm{CH}_{2}, 2 \mathrm{H}\right), 2.97$ (t, $J=7.3 \mathrm{~Hz}, \mathrm{~S}-\mathrm{CH}_{2}$, 2H), $1.73\left(\mathrm{tt}, J=7.3\right.$ and $\left.7.5 \mathrm{~Hz}, \mathrm{~S}-\mathrm{CH}_{2}-\mathrm{CH}_{2}, 2 \mathrm{H}\right), 1.70\left(\mathrm{tt}, J=7.3\right.$ and $7.5 \mathrm{~Hz}, \mathrm{~S}-\mathrm{CH}_{2}-$ $\left.\mathrm{CH}_{2}, 2 \mathrm{H}\right), 1.54-1.43\left(\mathrm{~m}, \mathrm{~S}-\left(\mathrm{CH}_{2}\right)_{2}-\mathrm{CH}_{2}, 4 \mathrm{H}\right), 1.42-1.33\left(\mathrm{~m}, \mathrm{~S}-\left(\mathrm{CH}_{2}\right)_{3}-\mathrm{CH}_{2}, 2 \mathrm{H}\right) \mathrm{ppm}$. ${ }^{13} \mathrm{C}$ NMR $\left(126 \mathrm{MHz}, \mathrm{CDCl}_{3}\right) \delta 154.6,149.8,144.8,143.9,138.4,136.1,133.2,133.2$, $132.6,132.6,128.6,128.6,127.5,127.5,127.3,127.3,127.1,127.1,123.8,123.8,123.2$, 
$123.2,118.9,118.5,113.6,110.7,33.0,32.2,28.8,28.7,28.63,28.60,28.58$ ppm. HRMS

(ESI, m/z): [M+Na]+ calcd. for $\mathrm{C}_{33} \mathrm{H}_{30} \mathrm{~N}_{4} \mathrm{NaS}_{2}, 569.1804$; found, 569.1782.

\section{Results and discussion}

Table 1 summarises the thermal phase sequences and phase-transition data, including the temperatures of crystallisation $\left(T_{\mathrm{Cr}}\right)$, glass transition $\left(T_{\mathrm{g}}\right), \mathrm{N}-\mathrm{N}_{\mathrm{TB}}$ transition $\left(T_{\mathrm{NNTB}}\right)$, and isotropic (Iso)-N transition ( $\left.T_{\mathrm{IN}}\right)$; as well as the entropy changes $(\Delta S)$ scaled by the gas constant $(R)$ at the Iso-N phase transition $\left(\Delta S_{\mathrm{IN}} / R\right)$ upon cooling at a rate of $10^{\circ} \mathrm{C} \mathrm{min}^{-1}$. The phase transitions that occurred during the first heating are presented in the Supporting Information.

Table 1. Phase-transition summary determined by POM and DSC at a cooling rate of $10{ }^{\circ} \mathrm{C} \mathrm{min}^{-1}$ for $(\mathrm{CN}) \mathrm{AzoS} n \mathrm{SAzo}(\mathrm{CN})$ and $(\mathrm{CN}) \mathrm{AzoS} n \mathrm{SCB}$.

\begin{tabular}{|c|c|c|c|c|c|c|c|c|c|c|}
\hline$(\mathrm{CN}) \mathrm{AzoS} n \mathrm{SAzo}(\mathrm{CN})$ & & $\begin{array}{c}T_{\mathrm{g}} \\
\left({ }^{\circ} \mathrm{C}\right)\end{array}$ & & $\begin{array}{c}T_{\mathrm{Cr}}\left({ }^{\circ} \mathrm{C}\right) \\
\left(\Delta H, \mathrm{~kJ} \mathrm{~mol}^{-1}\right)\end{array}$ & & $\begin{array}{c}T_{\mathrm{NNTB}}\left({ }^{\circ} \mathrm{C}\right) \\
\left(\Delta H, \mathrm{~kJ} \mathrm{~mol}^{-1}\right)\end{array}$ & & $\begin{array}{c}T_{\mathrm{IN}}\left({ }^{\circ} \mathrm{C}\right) \\
\left(\Delta H, \mathrm{~kJ} \mathrm{~mol}^{-1}\right)\end{array}$ & & $\Delta S_{\mathrm{IN}} / R$ \\
\hline$n=3$ & - & - & $\mathrm{Cr}$ & $205.9(54.5)$ & - & - & - & - & Iso & - \\
\hline 5 & - & - & $\mathrm{Cr}$ & $173.6(49.3)$ & $\mathrm{N}_{\mathrm{TB}}$ & $120^{\mathrm{a}}$ & - & - & Iso & - \\
\hline 7 & - & - & $\mathrm{Cr}$ & $125.4(45.4)$ & $\mathrm{N}_{\mathrm{TB}}$ & $121^{\mathrm{a}}$ & $\mathrm{N}$ & $169.7(1.60)$ & Iso & 0.43 \\
\hline 9 & - & - & $\mathrm{Cr}$ & $110.2(52.9)$ & $\mathrm{N}_{\mathrm{TB}}$ & 115.9 & $\mathrm{~N}$ & $163.4(2.34)$ & Iso & 0.65 \\
\hline 11 & - & - & $\mathrm{Cr}$ & $142.0(74.2)$ & $\mathrm{N}_{\mathrm{TB}}$ & $114^{\mathrm{a}}$ & $\mathrm{N}$ & $156.9(3.20)$ & Iso & 0.89 \\
\hline$(\mathrm{CN}) \mathrm{AzoS} n \mathrm{SCB}$ & & $\begin{array}{c}T_{\mathrm{g}} \\
\left({ }^{\circ} \mathrm{C}\right)\end{array}$ & & $\begin{array}{c}T_{\mathrm{Cr}}\left({ }^{\circ} \mathrm{C}\right) \\
\left(\Delta H, \mathrm{~kJ} \mathrm{~mol}^{-1}\right)\end{array}$ & & $\begin{array}{c}T_{\mathrm{NNTB}}\left({ }^{\circ} \mathrm{C}\right) \\
\left(\Delta H, \mathrm{~kJ} \mathrm{~mol}^{-1}\right)\end{array}$ & & $\begin{array}{c}T_{\mathrm{IN}}\left({ }^{\circ} \mathrm{C}\right) \\
\left(\Delta H, \mathrm{~kJ} \mathrm{~mol}^{-1}\right)\end{array}$ & & $\Delta S_{\mathrm{IN}} / R$ \\
\hline$n=3$ & - & - & $\mathrm{Cr}$ & $83.8(24.0)$ & $\mathrm{N}_{\mathrm{TB}}$ & $70^{\mathrm{a}}$ & $\mathrm{N}$ & $115.9(0.50)$ & Iso & 0.15 \\
\hline 5 & - & - & $\mathrm{Cr}$ & $82.3(18.4)$ & $\mathrm{N}_{\mathrm{TB}}$ & 98.2 & $\mathrm{~N}$ & $137.0(0.94)$ & Iso & 0.28 \\
\hline 7 & G & 15.7 & - & $-(-)$ & $\mathrm{N}_{\mathrm{TB}}$ & 101.4 & $\mathrm{~N}$ & $140.5(1.64)$ & Iso & 0.48 \\
\hline 9 & G & 16.0 & $\mathrm{Cr}$ & $57.2(6.7)$ & $\mathrm{N}_{\mathrm{TB}}$ & 101.1 & $\mathrm{~N}$ & $138.2(2.43)$ & Iso & 0.71 \\
\hline 11 & - & - & $\mathrm{Cr}$ & $107.0(50.8)$ & $\mathrm{N}_{\mathrm{TB}}$ & $98^{\mathrm{a}}$ & $\mathrm{N}$ & $134.2(3.41)$ & Iso & 1.01 \\
\hline
\end{tabular}

${ }^{\mathrm{a}}$ Determined by POM. 
The phase-transition behaviour of the symmetric homologous series, $(\mathrm{CN}) \mathrm{AzoSnSAzo}(\mathrm{CN})$, is described first. Using POM and DSC, symmetric homologues with $n=5,7,9$, and 11 revealed mesophases. $(\mathrm{CN})$ AzoS7SAzo $(\mathrm{CN})$, which exhibits an enantiotropic $\mathrm{N}$ phase and a monotropic $\mathrm{N}_{\mathrm{TB}}$ phase, has been reported previously [35]. The dimer with the shortest spacer, $(\mathrm{CN}) \operatorname{AzoS} 3 \mathrm{SAzo}(\mathrm{CN})$, was not mesogenic. $(\mathrm{CN})$ AzoS5SAzo $(\mathrm{CN})$ exhibited the monotropic $\mathrm{N}$ phase transition at approximately $171{ }^{\circ} \mathrm{C}$ upon cooling using POM, which could not be detected with DSC due to crystallisation at $173.6^{\circ} \mathrm{C}$. While the $\mathrm{N}$ phase gradually underwent crystallisation in the course of cooling, the small supercooled $\mathrm{N}$ textures were observed to transform into a blocky texture at approximately $120^{\circ} \mathrm{C}$ using POM, as shown in the Figure S3, indicating the elusive $\mathrm{N}_{\mathrm{TB}}$ formation. Meanwhile, the homologues with $n=9$ and 11 displayed the enantiotropic $\mathrm{N}$ phase and the monotropic $\mathrm{N}_{\mathrm{TB}}$ phase. The POM images of $(\mathrm{CN})$ AzoS9SAzo $(\mathrm{CN})$ are shown in Figure 2, representing a blocky texture typical of the $\mathrm{N}_{\mathrm{TB}}$ phase. The $\mathrm{N}_{\mathrm{TB}}$ temperature range from 115.9 to $110.2{ }^{\circ} \mathrm{C}$ of $(\mathrm{CN}) \mathrm{AzoS} 9 \mathrm{SAzo}(\mathrm{CN})$ was marginally broader than that of $(\mathrm{CN}) \operatorname{AzoS} 7 \mathrm{SAzo}(\mathrm{CN})$. As presented in the Figure $\mathrm{S} 12$, the $\mathrm{N}-\mathrm{N}_{\mathrm{TB}}$ transition at $115.9{ }^{\circ} \mathrm{C}$ was captured on the DSC curve, and was similar to the typical second-order $\mathrm{N}-\mathrm{N}_{\mathrm{TB}}$ phase transition characteristic of LC dimers. On the other hand, POM observation of the $\mathrm{N}_{\mathrm{TB}}$ phase at approximately $114{ }^{\circ} \mathrm{C}$ for $(\mathrm{CN})$ AzoS11SAzo $(\mathrm{CN})$ was challenging, since it could only be done in a considerably small supercooled $\mathrm{N}$ domain due to crystallisation at $142{ }^{\circ} \mathrm{C}$, as shown in the Figure $\mathrm{S} 4$. 

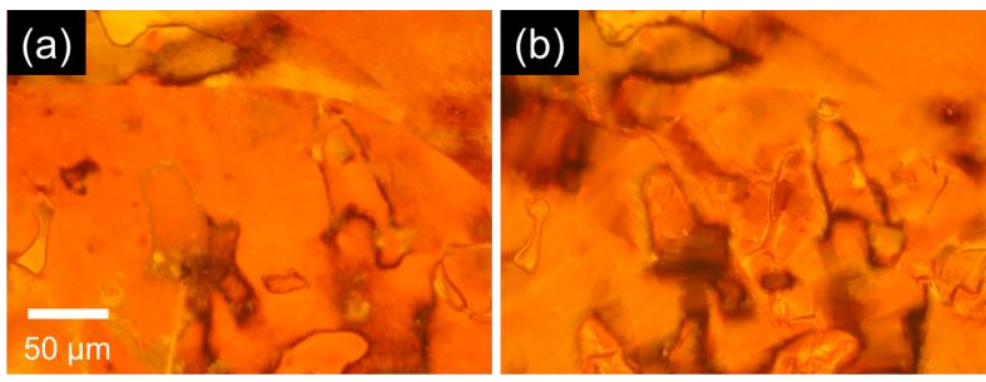

Figure 2. POM images of (a) $\mathrm{N}$ phase at $120{ }^{\circ} \mathrm{C}$ and (b) $\mathrm{N}_{\mathrm{TB}}$ phase at $115{ }^{\circ} \mathrm{C}$ for $(\mathrm{CN}) \mathrm{AzoS} 9 \mathrm{SAzo}(\mathrm{CN})$ with a non-treated glass cell.

Next, the phase-transition behaviour of the non-symmetric homologous series, (CN)AzoSnSCB, is explained. It is worth noting that all the non-symmetric (CN)AzoSnSCB dimers $\left(n=3,5,7,9\right.$, and 11) revealed the monotropic $\mathrm{N}_{\text {Tв }}$ phase in contrast to the symmetric $(\mathrm{CN}) \operatorname{AzoS} n \operatorname{SAzo}(\mathrm{CN})$ dimers, where only $n=5,7,9$, and 11 showed the $\mathrm{N}_{\text {Tв }}$ phase. The $\mathrm{N}_{\text {Tв }}$ phases of the dimers with the shortest and longest spacers, $(\mathrm{CN}) \mathrm{AzoS} 3 \mathrm{SCB}$ and $(\mathrm{CN}) \mathrm{AzoS} 11 \mathrm{SCB}$, respectively, were only observed in small supercooled $\mathrm{N}$ domains after crystallisation, as shown in the Figures S5 and S9, respectively. The DSC curves of (CN)AzoS5SCB are shown in Figure 3. (CN)AzoS5SCB exhibited the $\mathrm{N}-\mathrm{N}_{\mathrm{TB}}$ transition at $98{ }^{\circ} \mathrm{C}$ upon cooling. It is interesting to note that (CN)AzoS5SCB showed unique monotropic and enantiotropic mesophase behaviours due to crystal polymorphs depending on the thermal courses, as shown in Figure 3. Upon first heating for a recrystallised pristine sample, only one $T_{\mathrm{m}}$ at $144.6{ }^{\circ} \mathrm{C}$ or no mesophase was observed. Upon reheating after cooling to $0{ }^{\circ} \mathrm{C}$, the $\mathrm{Cr}^{\prime}-\mathrm{Cr}$ transition occurred at 93.6 ${ }^{\circ} \mathrm{C}$, giving a $T_{\mathrm{m}}$ at $143{ }^{\circ} \mathrm{C}$ and monotropic tendency similar to the first heating. However, upon reheating after cooling to $75^{\circ} \mathrm{C}$, the $\mathrm{Cr}-\mathrm{Cr}$ transition was not observed, and a hidden $\mathrm{N}$ phase emerged between 123.8 and $139.0^{\circ} \mathrm{C}$, indicating the existence of 
an enantiotropic $\mathrm{N}$ mesophase. The POM images for $(\mathrm{CN}) \mathrm{AzoS} 5 \mathrm{SCB}$ are shown in the Figures S6-S8. Notably, (CN)AzoSnSCB with $n=7$ and 9 exhibited the $\mathrm{N}_{\text {TB }}$ phase over considerably broader temperature ranges than the rest of the homologues. Figure 4 shows representative POM images of $(\mathrm{CN}) \mathrm{AzoS7SCB}$ with a non-treated glass cell. The $\mathrm{N}$ schlieren texture transformed into a blocky texture just below the $\mathrm{N}$ phase, and then polygonal, rope-like and focal conic textures appeared at lower temperatures, which are characteristic of the $\mathrm{N}_{\text {TB }}$ phase. The $\mathrm{N}-\mathrm{N}_{\text {TB }}$ phase transition detected at $101.4{ }^{\circ} \mathrm{C}$ in the DSC curve was observed at $\sim 103{ }^{\circ} \mathrm{C}$ using POM; this temperature corresponds to the onset of the transition in the DSC curve (Figure 5). The $\mathrm{N}_{\mathrm{TB}}$ textures of $(\mathrm{CN}) \mathrm{AzoS} 7 \mathrm{SCB}$ were preserved without crystallisation by cooling below room temperature. As evidenced by DSC (see Figure 5), the $\mathrm{N}_{\mathrm{TB}}$ phase was cooled to room temperature and vitrified at approximately $16{ }^{\circ} \mathrm{C}$. (CN)AzoS7SCB vitrified without crystallisation, whereas (CN)AzoS9SCB underwent partial crystallisation at $57{ }^{\circ} \mathrm{C}$ after the $\mathrm{N}-\mathrm{N}_{\mathrm{TB}}$ transition at 101.1 ${ }^{\circ} \mathrm{C}$, as detected with DSC at a rate of $10^{\circ} \mathrm{C} \min ^{-1}$ (see Figure S16). The discernible $T_{\mathrm{g}}$ at approximately $16{ }^{\circ} \mathrm{C}$ is ascribed to the supercooled partial $\mathrm{N}_{\mathrm{TB}}$ phase that did not crystallise, which is consistent with the POM observations (Figure 6). These are the first reported examples of azobenzene-based LC dimers exhibiting the $\mathrm{N}_{\mathrm{TB}}$ phase at room temperature. 

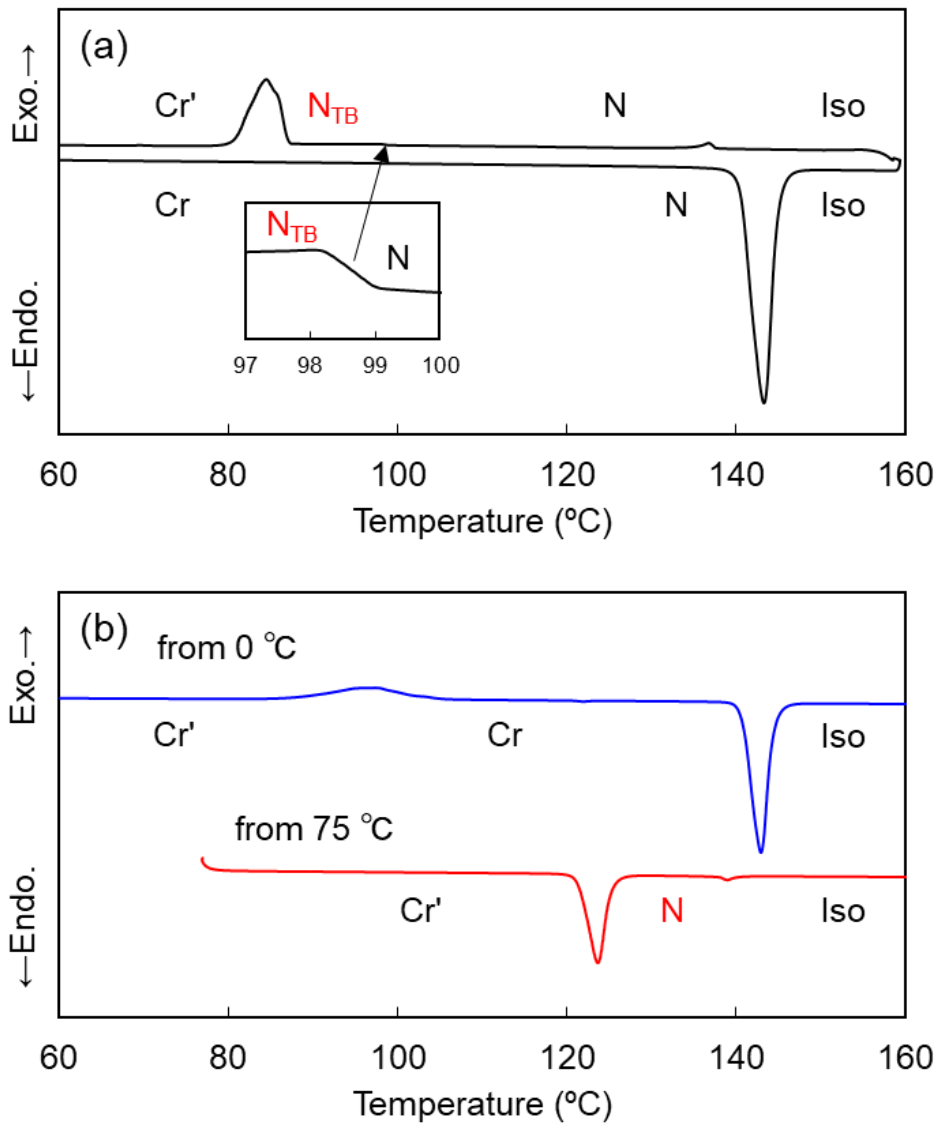

Figure 3. DSC curves of (CN)AzoS5SCB (a) upon first heating and first cooling and (b) reheating after cooling to $0{ }^{\circ} \mathrm{C}$ and $75^{\circ} \mathrm{C}$ at a rate of $10{ }^{\circ} \mathrm{C} \mathrm{min}-1$.
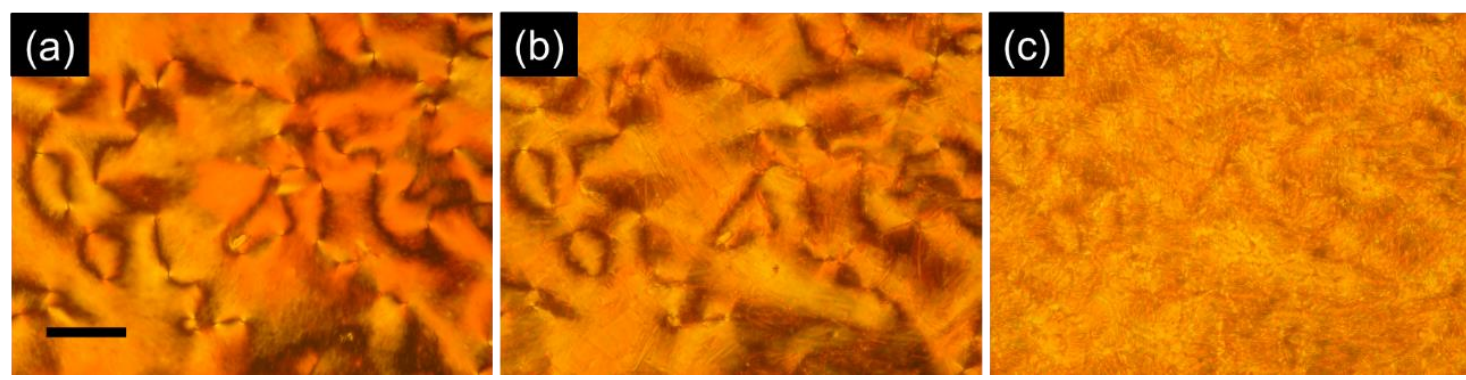

Figure 4. POM images of (a) $\mathrm{N}$ phase at $110{ }^{\circ} \mathrm{C}$ and $\mathrm{N}_{\mathrm{TB}}$ phase at (b) $100{ }^{\circ} \mathrm{C}$ and (c) $32{ }^{\circ} \mathrm{C}$ for $(\mathrm{CN})$ AzoS7SCB with a non-treated cell. 


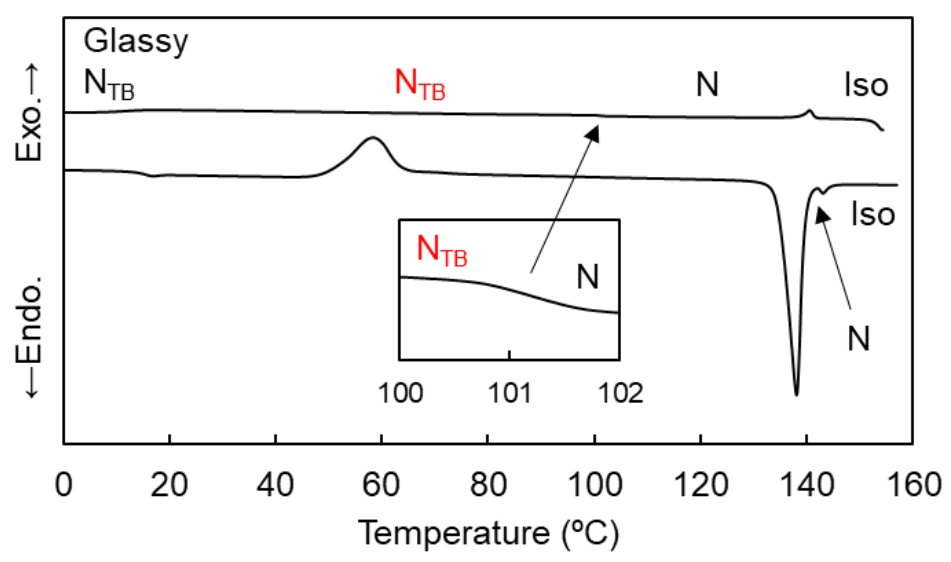

Figure 5. DSC curves of $(\mathrm{CN}) \mathrm{AzoS7SCB}$ upon first cooling and second heating at ate of $10{ }^{\circ} \mathrm{C} \mathrm{min}^{-1}$.
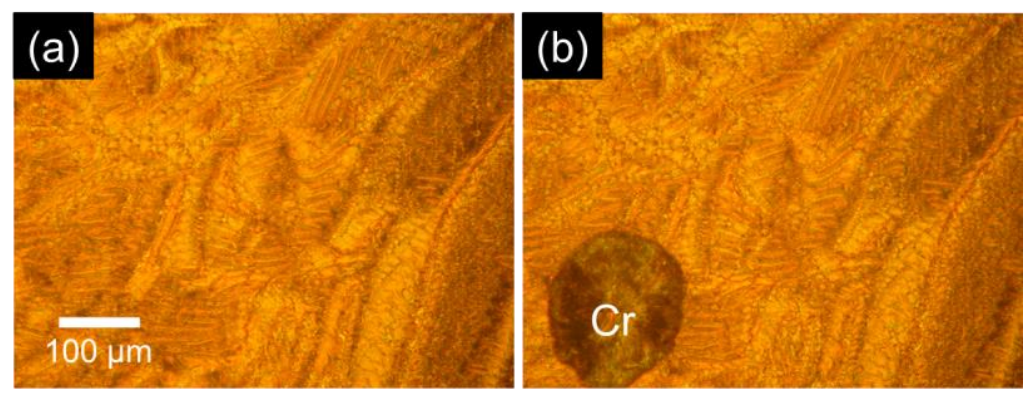

Figure 6. POM images of the $\mathrm{N}_{\mathrm{TB}}$ phase at (a) $70{ }^{\circ} \mathrm{C}$ and (b) $50{ }^{\circ} \mathrm{C}$ for $(\mathrm{CN}) \mathrm{AzoS} 9 \mathrm{SCB}$ with a non-treated glass cell.

XRD measurements of (CN)AzoS7SCB were also conducted to further characterise the observed mesophases. One-dimensional (1D) XRD patterns of the N and $\mathrm{N}_{\text {TB }}$ phase are shown in Figure 7 . In both phases, broadened diffraction peaks were detected in the wide-angle regions, corresponding to $d$-spacings of 4.61 and $4.51 \AA$ in the $\mathrm{N}$ (at $110{ }^{\circ} \mathrm{C}$ ) and $\mathrm{N}_{\mathrm{TB}}\left(\right.$ at $90{ }^{\circ} \mathrm{C}$ ) phases, respectively. These are associated with liquid correlations along the molecular transverse axes. On the other hand, no apparent small- 
angle diffractions were observed, indicating no apparent electron density modulation by layered structures or positional order. This is apparently different from the structurally

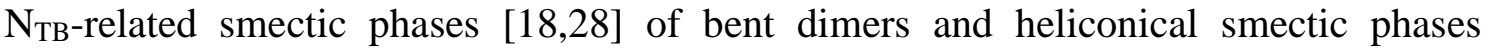
observed for bent-core molecules [88,89], which exhibit clear XRD peaks due to electron density modulation derived from layered structures in the small-angle region. Hence, the XRD results also underpin the $\mathrm{N}_{\mathrm{TB}}$ phase of the molecules. In addition, no extra diffractions were observed even at $30{ }^{\circ} \mathrm{C}$, indicating a glassy $\mathrm{N}_{\mathrm{TB}}$ state without crystallisation. Nevertheless, we can see very weak small-angle diffractions at $2 \theta=5.9^{\circ}$ in both the $\mathrm{N}$ and $\mathrm{N}_{\mathrm{TB}}$ phases, which are ascribed to the pseudo-layer nature due to molecular clusters in the fluid mesophases. The $d$-spacing of $15 \AA$ corresponds to almost half the dimer length, implying the presence of the so-called intercalated pseudo-layer structures between the aromatic mesogenic arm and the aliphatic spacer. The small-angle diffraction positions were almost unchanged in both the $\mathrm{N}$ and $\mathrm{N}_{\mathrm{TB}}$ phases, but became weaker after entering the $\mathrm{N}_{\text {тв }}$ phase, which is typical of the $\mathrm{N}_{\text {Tв }}$ phase.

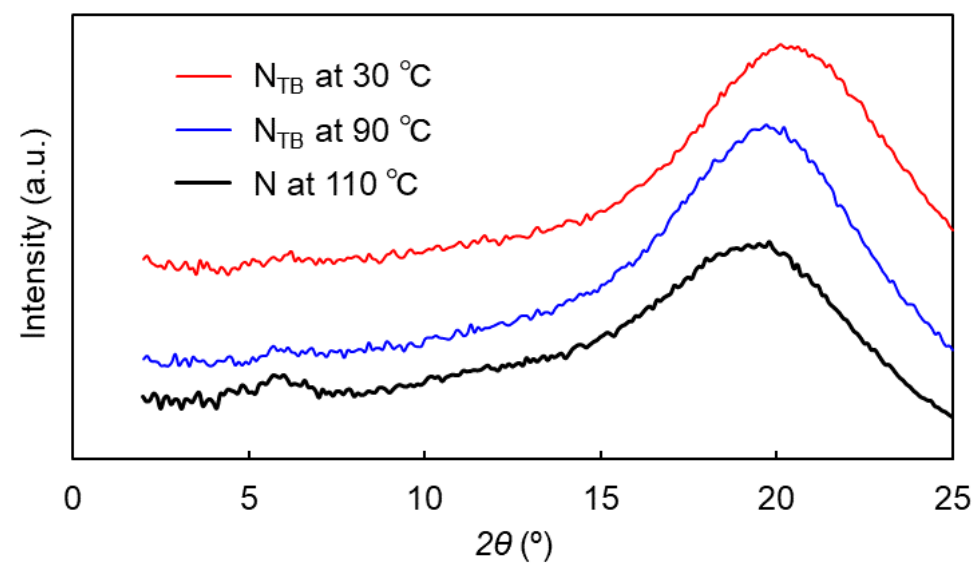

Figure 7. 1D-XRD profiles of $\mathrm{N}$ phase at $110{ }^{\circ} \mathrm{C}$ and $\mathrm{N}_{\mathrm{TB}}$ phase at 90 and $30{ }^{\circ} \mathrm{C}$ for (CN)AzoS7SCB. 
Next, the phase-transition behaviours of both homologous series were compared in terms of $T_{\mathrm{NNTB}}, T_{\mathrm{IN}}$, and $\Delta S_{\mathrm{IN}} / R$, which are plotted in Figure 8 as a function of $n$. Overall, the $T_{\mathrm{NNTB}}$ and $T_{\mathrm{IN}}$ values for the symmetric $(\mathrm{CN}) \mathrm{AzoS} n \mathrm{SAzo}(\mathrm{CN})$ dimers were higher than those for the non-symmetric $(\mathrm{CN}) \mathrm{AzoSnSCB}$ dimers, because the former series contains two 4-cyanoazobenzene arms, with larger intermolecular interaction than that of the counter 4-cyanobiphenyl arm of the latter series. It is noteworthy that $\Delta S_{\mathrm{IN}} / R$ of both series were very similar at the same $n$. This indicates that the different mesogenic arm structures (4-cyanoazobenzene or 4-cyanobiphenyl) do not significantly change the molecular anisotropy or geometries at the Iso-N phase transition. These results are consistent with previous results, which reported the molecular geometries at the Iso-N phase transition to be largely influenced by the linkage bonds rather than the mesogenic arms $[20,36]$. 

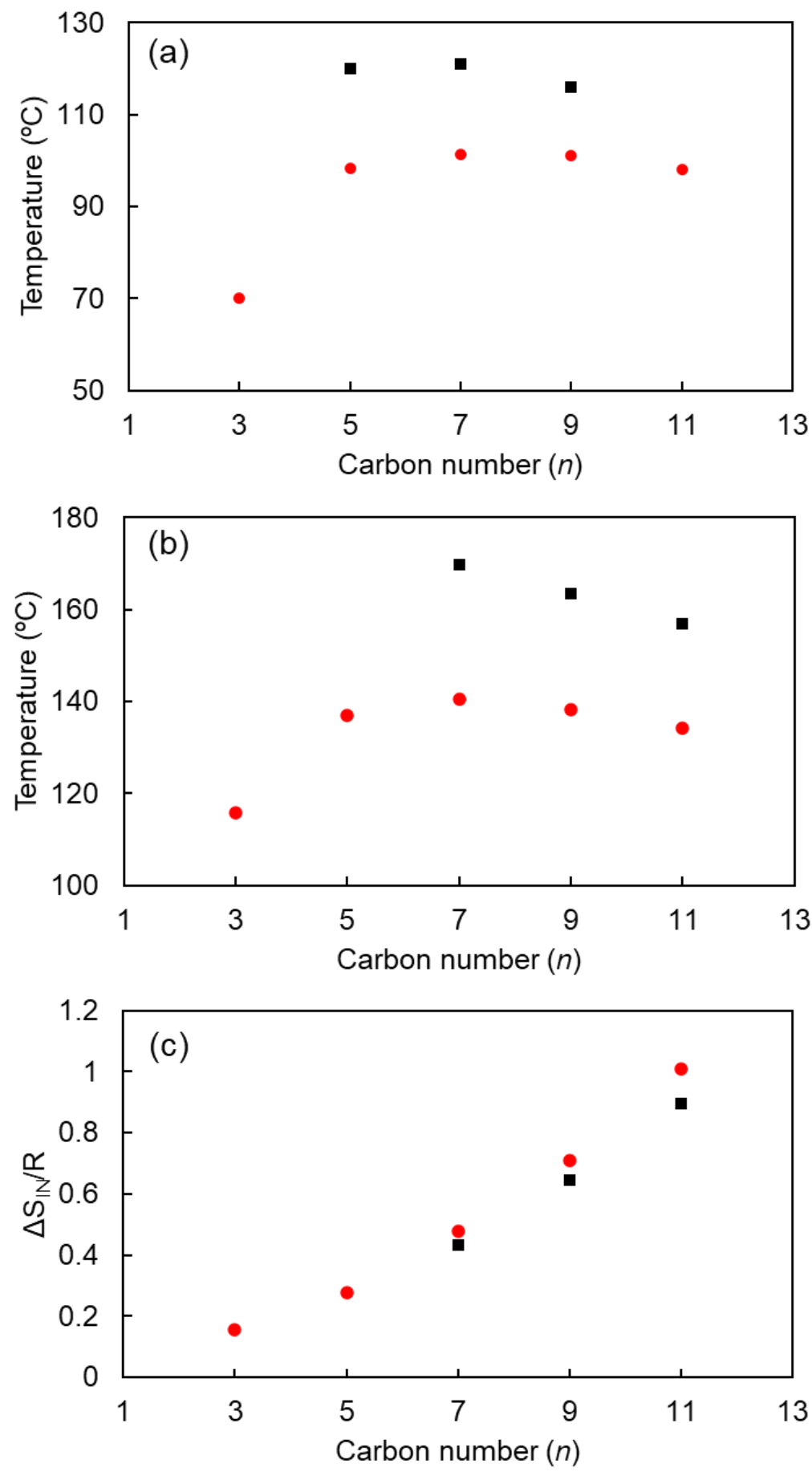

Figure 8. (a) $T_{\mathrm{NNTB}}$, (b) $T_{\mathrm{IN}}$, and (c) $\Delta S_{\mathrm{IN}} / R$ values as a function of $n$ for symmetric $(\mathrm{CN}) \mathrm{AzoS} n \mathrm{SAzo}(\mathrm{CN})$ (black squares) and non-symmetric $(\mathrm{CN}) \mathrm{AzoS} n \mathrm{SCB}$ (red circles). 


\section{Conclusions}

Two homologous series of thioether-linked 4-cyanoazobenzene-based LC dimers were prepared: a symmetric (CN)AzoSnSAzo $(\mathrm{CN})$ series and a non-symmetric (CN)AzoSnSCB series with a counter 4-cyanobiphenyl arm. The phase-transition behaviour was investigated. The symmetric $(\mathrm{CN}) \mathrm{AzoS} n \mathrm{SAzo}(\mathrm{CN})$ dimers with $n=5,7$, 9 and 11 formed elusive monotropic $\mathrm{N}_{\mathrm{TB}}$ phases. On the other hand, the asymmetric (CN)AzoSnSCB dimers all exhibited the $\mathrm{N}_{\mathrm{TB}}$ phase. Notably, $(\mathrm{CN}) \mathrm{AzoS} n \mathrm{SCB}$ ( $n=7$ and 9) formed $\mathrm{N}_{\mathrm{TB}}$ phases with a broad temperature range; they could even be cooled to room temperature and vitrified. These are the first reported examples of azobenzene-based LC dimers exhibiting the $\mathrm{N}_{\text {Tв }}$ phase over a broad temperature range and a glassy $\mathrm{N}_{\text {Tв }}$ phase below room temperature. This significant stability of the $\mathrm{N}_{\mathrm{TB}}$ phase was attributed to a supercooling effect assisted by the combination of molecular bend resulting from thioether linkages and non-symmetric mesogenic arm structures. Overall, the phasetransition temperatures were higher for symmetric $(\mathrm{CN}) \mathrm{AzoS} n \mathrm{SAzo}(\mathrm{CN})$ than for asymmetric $(\mathrm{CN}) \mathrm{AzoS} n \mathrm{SCB}$, whereas the difference in mesogenic arm structures or symmetry hardly impacted the molecular structural biaxiality or anisotropy at the Iso- $\mathrm{N}$ phase transitions. The present study adds new molecular structural insights with respect to azobenzene-based LC dimers exhibiting an extended range of $\mathrm{N}_{\mathrm{TB}}$ phase to room temperature. The sulfur-containing materials presented here are useful for investigations related to light-induced photoisomerisation and the resulting helical nano-structural variation of the $\mathrm{N}_{\text {Тв }}$ phase using tender resonant $\mathrm{X}$-ray scattering at the sulfur $\mathrm{K}$ edge, which is discussed in another report [90]. 


\section{Acknowledgements}

We are grateful to financial support from the Japan Society for the Promotion of Science

KAKENHI grant nos. 17K14493 and 20K15351, and research grants from the Naito

Foundation, the Toukai Foundation for Technology, and Toyohashi University of

Technology. We would like to thank Prof. Masatoshi Tokita (Tokyo Institute of

Technology) for use of the instruments for XRD measurements, and Ms. Tsugumi

Shiokawa and Dr. Hiroko Tada in the Division of Instrumental Analysis (Okayama

University) for the mass measurements.

\section{Declaration of interest statement}

The authors declare no conflict of interest.

\section{References}

[1] Ungar G, Feijoo JL, Keller A, et al. Simulataneous X-ray/DSC study of mesomorphism in polymers with a semiflexible mesogen. Macromolecules. 1990;23(14):3411-3416.

[2] Šepelj M, Lesac A, Baumeister U, et al. Dimeric salicylaldimine-based mesogens with flexible spacers: parity-dependent mesomorphism. Chem Mater. 2006;18(8), 2050-2058.

[3] Sěpelj M, Lesac A, Baumeister U, et al. Intercalated liquid-crystalline phases formed by symmetric dimers with an $\alpha, \omega$-diiminoalkylene spacer. J Mater Chem. 2007;17(12):1154-1165.

[4] Panov VP, Nagaraj M, Vij JK, et al. Spontaneous periodic deformations in nonchiral planar-aligned bimesogens with a nematic-nematic transition and a negative elastic constant. Phys Rev Lett. 2010;105(16):167801.

[5] Schröder MW, Diele S, Pelzl G, et al. Different nematic phases and a switchable SmCP phase formed by homologues of a new class of asymmetric bent-core mesogens. J Mater Chem. 2003;13(8):1877-1882.

[6] Yelamaggad CV, Shashikala IS, Li Q. Liquid crystal trimers composed of bananashaped and rodlike anisometric segments: synthesis and characterization. Chem Mater. 2007;19(26):6561-6568.

[7] Hann JL, Mandle RJ. Pentaerythritol Derived Tetrapode Exhibiting a Nematic-Like Mesophase at Ambient Temperatures. ChemPhysChem. 2020;20(15):1941-1945. 
[8] Meyer RB. Structural Problems in Liquid Crystal Physics, Molecular Fluids: Summer School in Theoretical Physics, les Houches lectures 1973 (Eds.: R. Balian, G. Weil). Gordon and Breach, New York, 1976, pp. 271-343.

[9] Dozov I. On the spontaneous symmetry breaking in the mesophases of achiral banana-shaped molecules. Europhys Lett. 2011;56(2):247-253.

[10] Memmer R. Liquid crystal phases of achiral banana-shaped molecules: a computer simulation study. Liq Cryst. 2002;29(4):483-496.

[11] Cestari M, Diez-Berart S, Dunmur DA, et al. Phase behavior and properties of the liquid-crystal dimer 1",7"-bis(4-cyanobiphenyl-4'-yl) heptane: a twist-bend nematic liquid crystal. Phys Rev E. 2011;84(3):031704.

[12] Henderson PA, Imrie CT. Methylene-linked liquid crystal dimers and the twist-bend nematic phase. Liq Cryst. 2011;38(11-12):1407-1414.

[13] Šepelj M, Baumeister U, Ivšić T, et al. Effects of geometry and electronic structure on the molecular self-assembly of naphthyl-based dimers. J Phys Chem B. $2013 ; 117(29): 8918-8929$.

[14] Mandle RJ, Davis EJ, Lobato SA, et al. Synthesis and characterisation of an unsymmetrical, ether-linked, fluorinated bimesogen exhibiting a new polymorphism containing the $\mathrm{N}_{\text {Тв }}$ or 'twist-bend' phase. Phys Chem Chem Phys. 2014;16(15):6907-6915.

[15] Mandle RJ, Davis EJ, Archbold CT, et al. Apolar bimesogens and the incidence of the twist-bend nematic phase. Chem Eur J. 2015;21(22):8158-8167.

[16] Mandle RJ, Goodby JW. Dependence of Mesomorphic Behaviour of MethyleneLinked Dimers and the Stability of the $\mathrm{N}_{\mathrm{TB}} / \mathrm{N}_{\mathrm{X}}$ Phase upon Choice of Mesogenic Units and Terminal Chain Length. Chem Eur J. 2016;22(27):9366-9374.

[17] Sebastián N, López DO, Robles-Hernández B, et al. Dielectric, calorimetric and mesophase properties of 1"-(2',4-difluorobiphenyl-4'-yloxy)-9"-(4cyanobiphenyl-4'-yloxy)nonane: an odd liquid crystal dimer with a monotropic mesophase having the characteristics of a twist-bend nematic phase. Phys Chem Chem Phys. 2014;16(39):21391-21406.

[18] Tamba MG, Salili SM, Zhang C, et al. A fibre forming smectic twist-bent liquid crystalline phase. RSC Adv. 2015;5(15):11207-11211.

[19] Ahmed Z, Welch C, Mehl GH. The design and investigation of the self-assembly of dimers with two nematic phases. RSC Adv. 2015;5(113):93513-93521.

[20] Mandle RJ, Voll CC, Lewis DJ, et al. Etheric bimesogens and the twist-bend nematic phase. Liq Cryst. 2016;43(1):13-21.

[21] Mandle RJ, Archbold CT, Sarju JP, et al. The dependency of nematic and twist-bend mesophase formation on bend angle. Sci Rep. 2016;6:36682.

[22] Dawood AA, Grossel MC, Luckhurst GR, et al. On the twist-bend nematic phase formed directly from the isotropic phase. Liq Cryst. 2016;43(1):2-12.

[23] Dawood AA, Grossel MC, Luckhurst GR, et al. Twist-bend nematics, liquid crystal dimers, structure-property relations. Liq Cryst. 2017;44(1):106-126.

[24] Paterson DA, Xiang J, Singh G, et al. Reversible isothermal twist-bend nematicnematic phase transition driven by the photoisomerization of an azobenzene-based nonsymmetric liquid crystal dimer. J Am Chem Soc. 2016;138(16):5283-5289.

[25] Paterson DA, Walker R, Abberley JP, et al. Azobenzene-based liquid crystal dimers and the twist-bend nematic phase. Liq Cryst. 2017;44(12-13):2060-2078.

[26] Abberley JP, Storey JM, Imrie CT. Structure-property relationships in azobenzenebased twist-bend nematogens. Liq Cryst. 2019;46(13-14):2102-2114.

[27] Ivšić T, Baumeister U, Dokli I, et al. Sensitivity of the $N_{T B}$ phase formation to the molecular structure of imino-linked dimers. Liq Cryst. 2017;44(1):93-105.

[28] Abberley JP, Killah R, Walker R, et al. Heliconical smectic phases formed by achiral molecules. Nat Commun. 2018;9:228.

[29] Knežević A, Sapunar M, Buljan A, et al. Fine-tuning the effect of $\pi-\pi$ interactions on the stability of the $\mathrm{N}_{\text {TB }}$ phase. Soft Matter. 2018;14(42):8466-8474. 
[30] Watanabe K, Tamura T, Kang S, et al. Twist bend nematic liquid crystals prepared by one-step condensation of 4-(4-Pentylcyclohexyl) benzoic acid and alkyl diol. Liq Cryst. 2018;45(6):924-930.

[31] Lesac A, Baumeister U, Dokli I, et al. Geometric aspects influencing N-N transition-implication of intramolecular torsion. Liq Cryst, 2018;45(7):1101-1110.

[32] Arakawa Y, Komatsu K, Tsuji H. Twist-bend nematic liquid crystals based on thioether linkage. New J Chem. 2019;43(17):6786-6793.

[33] Arakawa Y, Tsuji H. Selenium-linked liquid crystal dimers for twist-bend nematogens. J Mol Liq. 2019;289:111097.

[34] Cruickshank E, Salamończyk M, Pociecha D, et al. Sulfur-linked cyanobiphenylbased liquid crystal dimers and the twist-bend nematic phase. Liq Cryst. 2019;46(10):1595-1609.

[35] Arakawa Y, Komatsu K, Inui S, et al. Thioether-linked liquid crystal dimers and trimers: The twist-bend nematic phase. J Mol Struct. 2020;1199:126913.

[36] Arakawa Y, Ishida Y, Tsuji H. Ether- and Thioether-Linked Naphthalene-Based Liquid-Crystal Dimers: Influence of Chalcogen Linkage and Mesogenic-Arm Symmetry on the Incidence and Stability of the Twist-Bend Nematic Phase. Chem Eur J. 2020;26(17):3767-3775.

[37] Mandle RJ, Goodby JW. A Liquid Crystalline Oligomer Exhibiting Nematic and Twist-Bend Nematic Mesophases. ChemPhysChem. 2016;17(7): 967-970.

[38] Mandle RJ, Goodby JW. Progression from nano to macro science in soft matter systems: dimers to trimers and oligomers in twist-bend liquid crystals. RSC Adv. 2016;6(41):34885-34893.

[39] Al-Janabi A, Mandle RJ, Goodby JW. Isomeric trimesogens exhibiting modulated nematic mesophases. RSC Adv. 2017;7(75):47235-47242.

[40] Tuchband MR, Paterson DA, Salamończyk M, et al. Distinct differences in the nanoscale behaviors of the twist-bend liquid crystal phase of a flexible linear trimer and homologous dimer. Proc Natl Acad Sci USA. 2019;116(22):1069810704.

[41] Parsouzi Z, Babakhanova G, Rajabi M, et al. Pretransitional behavior of viscoelastic parameters at the nematic to twist-bend nematic phase transition in flexible nmers. Phys Chem Chem Phys. 2019;21(24):13078-13089.

[42] Mandle RJ, Al-Janabi A. Utilising Saturated Hydrocarbon Isosteres of para Benzene in the Design of Twist-Bend Nematic Liquid Crystals. ChemPhysChem. 2020;21(8):697-701.

[43] Simpson FP, Mandle RJ, Moore JN, et al. Investigating the Cusp between the nanoand macro-sciences in supermolecular liquid-crystalline twist-bend nematogens. $\mathrm{J}$ Mater Chem C. 2017;5(21):5102-5110.

[44] Wang Y, Singh G, Agra-Kooijman DM, et al. Room temperature heliconical twistbend nematic liquid crystal. CrystEngComm. 2015;17(14):2778-2782.

[45] Jansze SM, Martínez-Felipe A, Storey JMD, et al. A twist-bend nematic phase driven by hydrogen bonding. Angew Chem Int Ed. 2015;127(2):653-656.

[46] Mandle RJ, Goodby JW. A Nanohelicoidal Nematic Liquid Crystal Formed by a NonLinear Duplexed Hexamer. Angew Chem Int Ed, 2018;57(24):7096-7100.

[47] Stevenson WD, An J, Zeng XB, et al. Twist-bend nematic phase in biphenylethanebased copolyethers. Soft Matter. 2018;14(16):3003-3011.

[48] Chen D, Nakata M, Shao R, et al. Twist-bend heliconical chiral nematic liquid crystal phase of an achiral rigid bent-core mesogen. Phys Rev E. 2014;89(2): 022506.

[49] Sreenilayam SP, Panov VP, Vij JK, et al. The $\mathrm{N}_{\text {TB }}$ phase in an achiral asymmetrical bent-core liquid crystal terminated with symmetric alkyl chains. Liq Cryst. 2017;44(1):244-253.

[50] Xiang J, Li Y, Li Q, et al. Electrically tunable selective reflection of light from ultraviolet to visible and infrared by heliconical cholesterics. Adv Mater. 2015;27(19):3014-3018. 
[51] Wang Y, Zheng ZG, Bisoyi HK, et al. Thermally reversible full color selective reflection in a self-organized helical superstructure enabled by a bent-core oligomesogen exhibiting a twist-bend nematic phase. Mater Horiz. 2016;3(5):442446.

[52] Mrukiewicz M, Iadlovska OS, Babakhanova G, et al. Wide temperature range of an electrically tunable selective reflection of light by oblique helicoidal cholesteric. Liq Cryst. 2019;46(10):1544-1550.

[53] Prasad SK, Madhuri PL, Satapathy P, et al. A soft-bent dimer composite exhibiting twist-bend nematic phase: Photo-driven effects and an optical memory device. Appl Phys Lett. 2018;112(25):253701.

[54] Sridurai V, Kanakala MB, Yelamaggad CV, et al. Effect of gelation on the Frank elastic constants in a liquid crystalline mixture exhibiting a twist bend nematic phase. Soft Matter. 2019;15(48):9982-9990.

[55] Meyer C, Luckhurst GR, Dozov I. Flexoelectrically driven electroclinic effect in the twist-bend nematic phase of achiral molecules with bent shapes. Phys Rev Lett. 2013;111(6):067801.

[56] Borshch V, Kim YK, Xiang J, et al. Nematic twist-bend phase with nanoscale modulation of molecular orientation. Nat Commun. 2013;4:2635.

[57] Chen D, Porada JH, Hooper JB, et al. Chiral heliconical ground state of nanoscale pitch in a nematic liquid crystal of achiral molecular dimers. Proc Natl Acad Sci USA. 2013;110(40):15931-15936.

[58] Zhu C, Tuchband MR, Young A, et al. Resonant carbon K-edge soft X-ray scattering from lattice-free heliconical molecular ordering: soft dilative elasticity of the twistbend liquid crystal phase. Phys Rev Lett. 2016;116(14):147803.

[59] Stevenson WD, Ahmed Z, Zeng XB, et al. Molecular organization in the twist-bend nematic phase by resonant X-ray scattering at the Se K-edge and by SAXS, WAXS and GIXRD. Phys Chem Chem Phys. 2017;19(21):13449-13454.

[60] Salamończyk M, Mandle RJ, Makal A, et al. Double helical structure of the twistbend nematic phase investigated by resonant X-ray scattering at the carbon and sulfur K-edges. Soft Matter. 2018;14(48):9760-9763.

[61] Cao Y, Feng J, Nallapaneni A, et al. Identification of New Assembly Mode in the Heliconical Nematic Phase via Tender Resonant X-ray Scattering. 2019; arXiv:1907.11330.

[62] Vanakaras AG, Photinos DJ. A molecular theory of nematic-nematic phase transitions in mesogenic dimers. Soft Matter. 2016;12:2208-2220.

[63] Kumar A, Vanakaras AG, Photinos DJ. Polar Molecular Ordering in the $\mathrm{N}_{X}$ Phase of Bimesogens and Enantiotopic Discrimination in the NMR Spectra of Rigid Prochiral Solutes. J Phys Chem B. 2017;121:10689-10703.

[64] Vanakaras AG, Photinos DJ. Molecular dynamics simulations of nematic phases formed by cyano-biphenyl dimers. Liq Cryst. 2018;45(13-15):2184-2196.

[65] Heist LM, Samulski ET, Welch C, et al. Probing molecular ordering in the nematic phases of para-linked bimesogen dimers through NMR studies of flexible prochiral solutes. Liq Cryst. 2020;DOI:10.1080/02678292.2019.1711214.

[66] Samulski ET, Vanakaras AG, Photinos DJ. The twist bend nematic: a case of mistaken identity. 2020;arXiv:2006.00069.

[67] Hartley GS. The cis-form of azobenzene. Nature. 1937;140(3537):281-281.

[68] Tsutsumi O, Shiono T, Ikeda T, et al. Photochemical phase transition behavior of nematic liquid crystals with azobenzene moieties as both mesogens and photosensitive chromophores. J Phys Chem B. 1997;101(8):1332-1337.

[69] Yamamoto T, Nishiyama I, Yokoyama H. Novel photoinduced phase transition observed in three-dimensional liquid-crystalline phase of azobenzene compound. Chem Lett. 2007;36(9):1108-1109.

[70] Norikane Y, Hirai Y, Yoshida M. Photoinduced isothermal phase transitions of liquidcrystalline macrocyclic azobenzenes. Chem Commun. 2011;47(6):1770-1772. 
[71] Hori R, Furukawa D, Yamamoto K, et al. Light-Driven Phase Transition in a CubicPhase-Forming Binary System Composed of 4- $n$-Docosyloxy-3'-nitrobiphenyl-4carboxylic Acid and an Azobenzene Derivative. Chem Eur J. 2012;18(24):73467350.

[72] Hada M, Yamaguchi D, Ishikawa T, et al. Ultrafast isomerization-induced cooperative motions to higher molecular orientation in smectic liquid-crystalline azobenzene molecules. Nat Commun. 2019;10:4159.

[73] Yu Y, Nakano M, Ikeda T. Directed bending of a polymer film by light. Nature. 2003;425(6954):145-145.

[74] Pang X, Lv JA, Zhu C, et al. Photodeformable Azobenzene-Containing Liquid Crystal Polymers and Soft Actuators. Adv Mater. 2019;31(52):1904224.

[75] Ube T. Development of novel network structures in crosslinked liquid-crystalline polymers. Polym J. 2019;51(10):983-988.

[76] Shishido A. Rewritable holograms based on azobenzene-containing liquid-crystalline polymers. Polym J. 2010;42(7):525-533.

[77] Fukuhara K, Nagano S, Hara M, et al. Free-surface molecular command systems for photoalignment of liquid crystalline materials. Nature Commun. 2014;5:3320.

[78] Seki T. Light-directed alignment, surface morphing and related processes: recent trends. J Mater Chem C. 2016;4(34):7895-7910.

[79] Hendrikx M, Schenning AP, Debije MG, et al. Light-triggered formation of surface topographies in azo polymers. Crystals. 2017;7(8):231.

[80] Nagano S. Random Planar Orientation in Liquid-Crystalline Block Copolymers with Azobenzene Side Chains by Surface Segregation. Langmuir. 2018;35(17):56735683.

[81] Choi SW, Izumi T, Hoshino Y, et al. Circular-polarization-induced enantiomeric excess in liquid crystals of an achiral, bent-shaped mesogen. Angew Chem Int Ed. 2006;45(9):1382-1385.

[82] Vera F, Tejedor RM, Romero P, et al. Light-driven supramolecular chirality in propeller-like hydrogen-bonded complexes that show columnar mesomorphism. Angew Chem Int Ed. 2007;46(11):1873-1877.

[83] Alaasar M, Poppe S, Dong Q, et al. Mirror symmetry breaking in cubic phases and isotropic liquids driven by hydrogen bonding. Chem Commun. 2016;52(96):13869-13872.

[84] Vapaavuori J, Bazuin CG, Priimagi A. Supramolecular design principles for efficient photoresponsive polymer-azobenzene complexes. J Mater Chem C. 2018;6(9):2168-2188.

[85] Ahmed HA, Hagar M, Aljuhani A. Mesophase behavior of new linear supramolecular hydrogen-bonding complexes. RSC adv. 2018;8(61):34937-34946.

[86] Alaasar M, Schmidt JC, Darweesh AF, et al. Azobenzene-based supramolecular liquid crystals: The role of core fluorination. J Mol Liq. 2020;310:113252.

[87] Aya S, Salamon P, Paterson DA, et al. Fast-and-giant photorheological effect in a liquid crystal dimer. Adv Mater Interfaces. 2019;6(9):1802032.

[88] Sreenilayam SP, Panarin YP, Vij JK, et al. Spontaneous helix formation in non-chiral bent-core liquid crystals with fast linear electro-optic effect. Nat Commun. 2016;7:11369.

[89] Poppe M, Alaasar M, Lehman A, et al. Controlling the formation of heliconical smectic phases by molecular design of achiral bent-core molecules. J Mater Chem C. 2020;8(10):3316-3336.

[90] Feng C, Feng J, Saha R, et al. Manipulation of the nanoscale heliconical structure of a twist-bend nematic material with polarized light. Phys Rev Research. 2020;2:032004(R). 